\title{
¿Una pedagogía feminista para la enseñanza del Derecho?'
}

\author{
Uma pedagogia feminista Para a ensino do Direito?
}

\section{a feminist pedagogy for legal education?}

\author{
Karina Alejandra Andriola \\ https://orcid.org/0000-0001-9796-7899 \\ karinaandriola1@gmail.com \\ Facultad de Ciencias Jurídicas y Sociales | \\ Universidad Nacional de La Plata | Argentina
}

\section{RESUMEN}

La propuesta del trabajo es cuestionar e indagar a las pedagogías imperantes en las Facultades de Derecho públicas y más antiguas de Argentina en las cuales aprendimos un derecho patriarcal, androcéntrico, heterosexual y cis-género y a ser reproductor*s del mismo. A partir de allí presentamos la necesidad de una pedagogía feminista y reflexionamos sobre su implementación a partir de una experiencia pedagógica: una clase sobre "Violación y perspectiva de género" del seminario de grado sobre "Las mujeres y el Derecho Penal. El feminismo jurídico" de la Facultad de Ciencias Jurídicas y Sociales de la Universidad Nacional de La Plata, Argentina.

\section{RESUMO}

A proposta do trabalho é questionar e pesquisar as pedagogías imperantes nas Faculdades de Direito públicas e más antigas da Argentina, nas quías aprendemos um direito patriarcal, androcêntrico, heterossexual e cis-gênero e reproducir o mismo. Posteriormente aprensentamos a necessidade de uma pedagogia feminista e refletimos sobre sua implementação en uma aula sobre "Perspectiva de Gênero e Estrupo" de um seminário sobre "Mulheres e Dereito Penal. O Feminismo Jurídicos" da Faculdade de Ciências Jurídicas e Sociais da Universidade Nacional de La Plata, Argentina.

$1 \quad$ El presente trabajo forma parte de una línea de investigación que comenzamos a mediados del año 2018, donde los primeros resultados de la misma fueron presentados y debatidos en IX Jornadas sobre Enseñanza del Derecho, realizadas en la 3 y 4 de octubre de 2019, Facultad de Derecho (UBA) en el Eje temático: Enfoque de género.
PALABRAS CLAVE

Educación jurídica, Feminismos, Pedagogía, Perspectiva de género y diversidad, Violación.

PALAVRAS CHAVES

Educação jurídica, Feminismos, Pedagogía, Perspectiva de Gênero e diversidade, Estrupo. 


\section{KEY WORDS}

Legal education, Feminist,

Pedagogy,

Gender and diversity

perspective,

Rape.

\section{ABSTRACT}

The paper propose to questión and researche the leading teaching in the oldest and public Law School in Argentina in wich we lear a patriarchal, androcentric, heterosexual and cis-gender law and to replacate it. In that sense we explain the need of a feminist pedagogy and reflect about a class call " Gender Perspectiva and rape" in the "Woman and Criminal Law. Legal Feminist" in the Law and Social Science School of the National University of La Plata, Argentina. 


\section{I) ENCUENTROS CON LA TEMÁTICA Y PUNTOS DE PARTIDA}

El trabajo surge como parte de mi reflexión y práctica cotidiana como docente e investigadora. Reconstruyendo mi trayectoria como mujer feminista blanca y lesbiana, en un espacio patriarcal, heteronormativo, cisgénero, endosexual y binario ${ }^{2}$ como es la Facultad de Ciencias Jurídicas y Sociales de la UNLP ( en adelante FCJyS ) reflexiono como docente de grado, de postgrado, y de diferentes seminarios de grado vinculados a género y diversidad sexual, además de mi participación el Aérea de Estudios de Género del Instituto de Cultura Jurídica, en la Red de Profesoras, descripción que forma parte de mi posicionamiento epistemológico feminista (Blazquez Graf 2012) y queer ${ }^{3}$. Reflexiono también como graduada de la Especialización en Docencia Universitaria de la UNLP en la cual investigue para mi Trabajo Final Integrador la incorporación de la perspectiva de género en el Derecho de las Personas y el Derecho de las Familias (Derecho Civil V), recorrido que sumado a una experiencia de clase me incentivaron a pensar la pedagogía que utilizo y que en su momento utilizaron para conmigo como estudiante no hace tantos años.

Luego de ser convocada a organizar y participar en un clase (italler?) en una cursada de Derecho de las Familias sobre género en

2 La heteronormatividad hace referencia al régimen social y político que considera únicamente como aceptable que el deseo sexual, afectivo relacional se de entre personas que se identifican como opuestas dentro del binario varón-mujer, la cis sexualidad refiere a los casos en que la identidad de género de la persona corresponde con el sexo asignado al nacer y la endosexualidad refiere a las corporalidades que se adaptan al binarismo de los cuerpos clasificados como de varón o de mujer, con anatomías y fisiologías diferentes.

3 "Queer" significa en inglés significa "raro/a" y es utilizada como un eufemismo para referirse a gays y lesbianas de manera despectiva y fue re- significada para referirse a los estudios sobre el tema, las

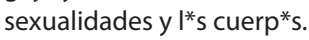


agosto de 2019 en conjunto con otra expositora, externa a la Facultad, formada en humanidades con quien no logramos previamente consensuar la modalidad de la intervención comencé a preguntarme ¿es necesario proponer y pensar una pedagogía feminista que desnaturalice e identifique los recursos didácticos con los que nos fue transmitido y enseñado un derecho patriarcal?, ¿resultan adecuadas las mismas estrategias didácticas para trasmitir un derecho patriarcal o un derecho con perspectiva de género y diversidad?, ¿es necesario pensar en otras prácticas de intervención que construyan espacios de aprendizaje más igualitario, con las dificultades y resistencias que ello implica?

¿es necesario proponer y pensar una pedagogía feminista que desnaturalice e identifique los recursos didácticos con los que nos fue transmitido y enseñado un derecho patriarcal?, ¿resultan adecuadas las mismas estrategias didácticas para trasmitir un derecho patriarcal o un derecho con perspectiva de género y diversidad?, ¿es necesario pensar en otras prácticas de intervención que construyan espacios de aprendizaje más igualitario, con las dificultades y resistencias que ello implica?

Acorde con ello la propuesta del trabajo es ensayar algunos fundamentos acerca de la necesidad de reflexionar sobre las estrategias didácticas implementadas cuando enseñamos una asignatura, o al menos determinados contenidos con perspectiva de género y diversidad. Reflexiones teóricas que pudieran ponerse en dialogo con su aplicación práctica en una clase y la necesidad de una pedagogía feminista para llevar adelante dicha tarea. Pedagogía feminista que ha sido mayormente explorada en el ámbito de la educación popular (Macías Ochoa, 2008, Korol, 2007) o con un enfoque postcolonial (Martínez Marín, 2016) pero que es escasamente explorada en la educación jurídica donde los principales aportes y discusiones vinculados al género se dan en torno a la incorporación de las mujeres y los lugares que ellas ocupan (Andriola, 2014), los programas existentes para eliminar las discriminaciones, las investigaciones especializadas sobre el tema (Buquet Corleto, 2011), la incorporación de la perspectiva de género y diversidad y su transversalización. Existen varias publicaciones donde se analiza dicha presencia en los diseños curriculares (Calzadilla Medina y Hernández Torres 2018, Ditieri y Cortese 2019, Zaikosky Biscay, 2018, González 2019, Ronconi 2020,), en los criterios de CONEAU para acreditar las carreras (Piccone, 2018), en la incorporación en asignaturas puntuales (Cano 2019, Andriola y Cano, 2017, Andriola 2018, Heim 2019, Di Corleto, 2020, Herrera 2017, Zaikosky 2019, entre otras) o los aportes de los feminismos jurídicos como parte de los contenidos 
(Bauger, 2019, Costa Weigman, 2017, Lerussi, 2017).

En ese sentido primero haremos algunas consideraciones sobre las estrategias didácticas predominantes en la educación jurídica ofrecida por las Facultades de Derecho públicas y la enseñanza patriarcal que implican y posteriormente nos abocaremos a los aportes de la(s) pedagogía(s) feministas y por último la reconstrucción y reflexión sobre una experiencia educativa que nos permita pensarla a la luz de la(s) pedagogías feministas.

\section{II) DEFINICIONES ¿NECESARIAS?: FEMINISMO Y PERSPECTIVA DE GÉNERO Y DIVERSIDAD.}

Si bien el objeto del presente trabajo no es abocarnos ni profundizar sobre la perspectiva de género y diversidad en sí misma ni en los feminismos nos resulta imprescindible hacer referencia a que entendemos como parte de dichas categorías teóricas. Si bien los feminismos según Fries Monleon y Lacrampettte Polanco (2013:33) "comprenden un conjunto de teorías criticas que explican la subordinación, dominación , explotación y/o marginación de las mujeres en la sociedad y promueven su plena emancipación" compartimos con Misse y Solá García la idea entender al feminismo como "el lugar en el que nos posicionamos frente a una sociedad que utiliza el género como mecanismo de dominio, control y explotación" (2009:3), desde un feminismo donde el sujeto político: "mujeres" no es entendida como categoría homogénea y universal desconociendo su construcción burguesa, blanca y europea, heterosexual, así como tampoco "entendida en forma biologicista, excluyente y normativa" (2009:3), incluso contemplando las posibilidades del trans-feminismo, reconociendo que no existe un feminismo único ni mejor que otro (Martínez Marín, 2016: 131).

Feminismos que nos permiten considerar la perspectiva de género como aquella que "alude al orden simbólico con que una cultura dada elabora la diferencia sexual" y la utiliza "para describir cómo opera la simbolización de la diferencia sexual en las prácticas, discursos y representaciones culturales sexistas y homófobas" (Lamas 1999, $\mathrm{s} / \mathrm{n})$. Perspectiva de género que "identifica y propone eliminar las discriminaciones reales de que son objeto las mujeres, por mujeres y los hombres, por hombres" (Lamas 1996:8). Uso de la categoría "mujer"la cual nos abre a la pregunta a quienes hablamos (por ejemplo, incluso reproduciendo el binarismos, ¿hablamos de mujeres trans y cis-género o bien de femeneidades, de mujeres heterosexuales, bisexuales, pansexuales y lesbianas?) y si resulta una terminología acorde a la evolución de la teoría queer y una interpretación y aplicación de los derechos humanos que reconozca y respete las singularidades. Como señalamos previamente ( Andriola, 2019b) hacemos referencia a la perspectiva de género y diversidad para develar la heteronorma- 
tidad, cisgeneridad y endosexualidad del derecho la cual habilita a conocer"la forma en que se disciplina dentro en el ámbito jurídico los saberes referidos al vasto campo de lo que hasta el momento -y en un gesto de simplificación- hemos denominado género, tiende a la instauración de un canon que incorpora ciertos saberes a costa de la negación de otros" (Viturro, 2005:297). En ese sentido y complementario a ello resultan pertinentes los aportes de Heim (2018) quien la plantea relacionada con

"mirar y analizar el derecho desde un punto de vista crítico con respecto a ... dónde, cómo y por quiénes ha sido producido (y se produce); cuáles son sus contenidos; dónde, cómo y por quiénes se aplica y qué podemos esperar de él, teniendo en cuenta los sesgos de género presentes en los citados procesos y resultados, así como la desigualdad social estructural ...ello supone, básicamente, revelar las opresiones sexuales y de género del patriarcado y hacer visible a las mujeres y al resto de personas oprimidas por este sistema, sacándolas de donde han permanecido ocultas y trayendo con ellas sus experiencias, emociones, sentimientos y formas de expresarse en el mundo. En consecuencia, la perspectiva de género no sólo amplía los horizontes de comprensión de nuestra realidad y da complejidad a los tamices a través del cual los percibimos, sino que se convierte en un instrumento puesto al servicio de la justicia social.... La perspectiva de género requiere, también, de la necesidad de entender el derecho no como un instrumento en sí mismo sino como un espacio de lucha para la transformación social, que se articulará con otros elementos puestos al servicio de esta finalidad (Smart, 2000: 32-33)" (2019 s/f)

Categorías que vamos a analizar en un contexto de socialización de quienes se forman para ser abogad*s: las Facultades de Derecho.

\section{III) RECORRIDOS, ENSEÑANZA PATRIARCAL Y ESTRATEGIAS DIDÁCTICAS}

Consideramos pertinente plantear algunos puntos de partida implícitos, naturalizados en la educación jurídica y en el campo de la investigación. En esta ultima existen algunos consensos sobre la necesidad de incorporar la perspectiva de género a las línea de investigación siendo según Busquet Corletto (2011), Gonzalez (2019) y Zaikosky Biscay (2018) como una de las vías, pero no la única para transversalizar la perspectiva de género, además de explicitar la epistemología

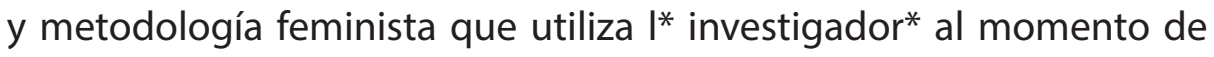
producir conocimiento. A su vez resulta imprescindible trasladar la explicitación de la perspectiva pedagogía desde la cual se aborda el proceso de enseñanza y aprendizaje propuesto por l* docentes y el cual también aceptan, demandan o se resisten ${ }^{*}$ s estudiantes 
Consideramos pertinente plantear algunos puntos de partida implícitos, naturalizados en la educación jurídica y en el campo de la investigación. En esta ultima existen algunos consensos sobre la necesidad de incorporar la perspectiva de género a las línea de investigación siendo según Busquet Corletto (2011), Gonzalez (2019) y Zaikosky Biscay (2018) como una de las vías, pero no la única para transversalizar la perspectiva de género, además de explicitar la epistemología y metodología feminista que utiliza I* investigador* al momento de producir conocimiento.

En ese sentido diferentes líneas de investigación empírica y teórica sobre educación jurídica han podido identificar modelos pedagógicos imperantes en la enseñanza del Derecho en la FCJyS donde prevalecen las prácticas asociadas a las clases magistrales y la enseñanza dogmática y bancarizada (González y Cardinaux 2009, González y Gabriela, 2014, Andriola 2018, Ditieri y Cortese, 2009, Herrera, 2017, Zaikosky 2019, Kennedy 2004, Benente 2017). Allí la propuesta de enseñanza y aprendizaje se reduce en la mayoría de las oportunidades a recitar y analizar un texto normativo, manuales en una buena parte de las oportunidades escritos por I*s prop*s titulares de cátedra, desprendido de su historicidad y de las problemáticas sociales que interpelan a la realidad a los/as/es operadores y que hacen al efectivo reconocimiento de los derechos humanos de las personas.

La estrategia -llamémosle- "didáctica" de la clase magistral implica repetir por l*s estudiantes en el momento de la evaluación aquello que $I^{*}$ docente quien como

plantea Ávila Cambeiro "es el protagonista del proceso y también lo es su capacidad para narrar, dejando al alumno en un papel secundario, el profesor es quien organiza los materiales y los presenta a los alumnos a través de una exposición que resulta abstracta, tanto de datos como de métodos conceptos...." (2014,119). Didáctica tradicional desde la cual no es posible enseñar el derecho desde la teoría crítica.

A su vez también resulta importante tener en consideración que "las visiones tradicionales del Derecho y de la pedagogía, constituyen a reproducir las estructuras y los habitus de I*s agentes y por ello, a sostener las desigualdades sociales que resultan negadas (invisibilizadas) al enfatizar dogmáticamente, la igualdad ante la ley y la igualación e inclusión social a través de la enseñanza pública" (Bianco y Marano 2008,589). Incluso como plantea Costa Wesgman las aulas de las Facultades de Derecho han "resultado lugares de (re)creación y entrenamiento del personal jurídico" donde el acento está puesto en "lo que conserva y no en lo que crea. De allí que la experiencia educativa, en especial en las aulas de derecho, sea enfáticamente conservadora" $(2017,48)$. 
Al respecto resultan pertinentes los aportes de Benente (2017) quien parte de la premisa de Kennedy (2004) quien considera a las facultades de derecho lugares inmensamente político en los cuales I*s estudiantes se preparan para la jerarquía, la cual se sustentan no solo en los contenidos de la carrera sino también en las prácticas autoritarias que se desarrollan dentro de las aulas (2017:182). En dichos espa-

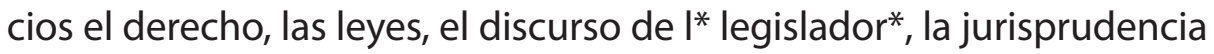
y los comentarios que esta recibe e incluso las dinámicas institucionales se muestran totalmente despolitizadas, con saberes negados, y descontextualizados parte de un discurso que no inscribe "al derecho en procesos históricos, económicos, sociales, que atraviesan a gran parte del relato jurídico con independencia del posicionamiento político e ideológico" (2017:183).

Al respecto plantea como contribuyen a dicho conservadurismo "los relatos de en los cuales socializan o se subjetiva I*s estudiantes" durante la formación que reciben en las facultades sea porque consoliden los discursos conservadores provenientes de otras instituciones así como también porque no logran desarticularlos. En dicho análisis retomando a Kennedy, Benente pone a I*s estudiantes en el escenario y como actores de dicha educación jurídica mencionando al respecto la responsabilidad de $I^{*} s$ docentes cuya alternativas emancipadoras no se encuentran en los cánones pedagógicos tradicionales que son embrutecedores y subordinan la inteligencia de $\mathrm{I}^{*} \mathrm{~s}$ estudiantes frente a la de I*s docentes.

Volviendo a la experiencia de clase señalada en el título anterior que originó esta reflexión: La actividad duraba dos horas y media aproximadamente y en función de los contenidos propusimos que comenzara la otra expositora por ser más teóricos y generales, en el entendimiento "implícito" de que la división de tiempo se daría en partes iguales, tanto por respeto al trabajo de ambas, como de la propuesta tanto teórica como práctica. La sorpresa fue importante cuando nos encontramos con una clase expositiva de una expositora feminista, donde provenir de otra Facultad, tener otra formación lejos estaba romper con la lógica de la clase magistral, bancarizada, donde el tiempo relegado a mi propuesta de taller quedo en mucho menos de la mitad y ante lo cual nos empezamos a preguntar ¿qué diferencia esta intervención de la de cualquier* docente titular que transmite y enseña un derecho patriarcal, androcéntrico, heteronormativo y cis-genero? A nuestro entender, más allá del cambio de los contenidos o el género de quien exponía - partiendo de que la FCJyS lejos está de la paridad y se ve claramente el techo de cristal en torno al acceso a cargos de docentes de mayor jerarquía-, no había ninguna.

La segunda pregunta que nos hicimos fue si el cambio de contenidos, patriarcales o con perspectiva de género y diversidad ¿implica un cambio en la formas de enseñar casi automáticamente?, nuevamente la res- 
puesta fue negativa. Abriéndonos a la necesidad de pensar no solo en los contenidos, de lo cual existe una abundante producción teórica sino también las estrategias que utilizamos como parte de una pedagogía feminista que implique proponer otras formas de aprender rompiendo con las lógicas patriarcales donde la educación, tanto en la formación profesional como en la socialización, tiene un rol preponderante.

\section{IV) APROXIMACIONES A LA(S) PEDAGOGÍA(S) FEMINISTA(S).}

En este punto, es importante desarrollar que entendemos por "pedagogía feminista", sus bases, alcances e importancia incluso en el entendimiento de que no hay un consenso difundido y reconocido en diferentes círculos respecto de la existencia de una o varias pedagogía (s) feminista (s) (Macías Ochoa, 2008) y que es diferente hablar de educación y género que de pedagogía feminista. Por lo cual los aportes que esbozamos son provisorios partiendo del presupuesto de que la educación no es neutral "ya que, o bien pueden ser responsables de normalizar y reproducir sociedades desiguales, o bien pueden servir como herramientas de transformación para ciudadanías en igualdad" (Martínez Marín 2016:130).

Sobre el tema pueden encontrarse varias definiciones, en su mayoría convergente y/o complementaria que comparten la premisa común de procurar la eliminación cultural y política de la opresión de género, la transformación de la sociedad, la libertad y autonomía individuales y colectivas (Maceiro Ochoa 2006:31). La mexicana4 Ríos Everardo quien se aboca a la educación escolar, identifica a la pedagogía feminista como aquella que viene "al romper con la racionalidad pedagógica androcéntrica, que implica prioritariamente la crítica del patriarcado y del sexismo en la vida, en la escuela y en todo tipo de institución social, y cuestiona las formas de introyectar la desvalorización y opresión e inequidad social en las mujeres (2005: 126). Lagarde plantea para ello identificar -a los fines de su transformación-, "las situaciones y condición de vida de las mujeres y de los hombres en un contexto histórico, económico y social determinado de manera integral, lo que implica primero situar a las personas". Lo cual dentro de nuestra visión afín al transfeminismo habilitaría a pensar más allá de dicho binarismo, visibilizarlo e incluir a otros colectivos oprimidos.

Relacionado con ello Maceiro Ochoa entiende como pedagogía feminista, "un conjunto de discursos, una práctica política, y es también una manera específica de educar. Su especificidad consiste en echar una nueva mirada a propuestas político-pedagógicas emancipadoras y desde una postura ética, filosófica y política denunciar su parcialidad y su androcentrismo, posicionándose críticamente ante el poder y la

$4 \quad$ Partiendo de una epistemología feminista decidimos incluir el país desde el cual producen conocimiento las autoras citadas, pudiendo identificar en dicha explicitación los alcances, contextos y limitaciones del mismo. 
dominación masculinos, y promoviendo la libertad y el fortalecimiento de las mujeres, para construir de manera colectiva una sociedad más libre y democrática" (Maceiro Ochoa y 2007: 3). Ello responde a la necesidad "de ser reconocidas como sujetas, de eliminar todo tipo de opresión de género" y "busca la construcción de un proyecto de sociedad diferente, sin opresión ni subordinación femenina, sin ningún tipo de discriminación y con mayor justicia y libertad para todas las personas y que demanda la formación y trabajo de tod*s "independientemente" de su género, por ello, incluso dentro del binarismo, explicita que es "una pedagogía para hombres y para mujeres."

En ese sentido la autora considera a la pedagogía feminista

como una herramienta que potencia y autonomiza al ser humano... asumiendo que cada persona es y debe formarse diferente, diferenciada, diferenciándose... la cuestión central "no es comprender y respetar" las diferencias, como han escrito algunas autoras al proponer una "educación pluralista, diversa y no sexista", ni hacer una suerte de intercambio de valores y roles tradicionales como sugieren algunas propuestas coeducativas, sino liberar las diferencias, abrir la posibilidad de múltiples opciones. Esta apertura forma parte de un cambio subjetivo y cultural que permita a cada persona pensar por sí misma, autorizarse a formular nuevas imágenes de sí, partir de lo que desea, sin atender a mandatos e imposiciones culturales, jerárquicos, excluyentes (2006: 32).

Sumado a ello plantea que "el proceso educativo es un ejercicio de creatividad, de soñar, de imaginación de horizontes, de identificación de deseos, y de construcción de elementos simbólicos que favorezcan la reflexión, la crítica, y el cambio de esquemas que impiden la libre y plena realización de cada persona" (2007:3). En el cual se destaca como rasgo característico "la transgresión como producto del aprendizaje. La pedagogía feminista es una pedagogía... para realizar pequeñas y grandes revoluciones, que empieza con el ejercicio de pequeñas rebeldías y pretende hacer cambios radicales amplios" y que incluyen y atraviesan lo personal. Retomando a Lagarde postula que

inaugura paradigma, implica que trastoques las estructuras, que transformes las instituciones y normas, implica el empoderamiento, la autonomía, la independencia, la acumulación de poderes para desmontar estructuras patriarcales y opresivas, y para construir alternativas. Para la pedagogía feminista el aprendizaje es permanente. Es tanto teórico como práctico, objetivo y subjetivo, multidimensional e integral, colectivo, dialógico, lúdico y placentero. El proceso de aprendizaje es completamente personal, íntimo, al propio ritmo, gradual, lento, complejo. Requiere entre otras cosas de paciencia y respeto, la valoración de las capacidades individuales, y también espacios para su experimentación 
pues en los proyectos educativos feministas se promueven aprendizajes para la vida que implican consecuencias no sólo cognitivas sino también emotivas, subjetivas, actitudinales y prácticas. En este sentido, los procesos educativos feministas implican valores, ideas y productos que se viven, se experimentan, se buscan aterrizar en una acción o una forma de hacer o de ser, suponen siempre una vuelta a la experiencia cotidiana pues busca generar alternativas, es una educación transformadora. $Y$ aunque los niveles y alcances de esa acción buscada sean diferenciados, pretenden convertirse en experiencias vitales, sistemáticas -no en experiencias únicas- de una vida, un hacer, un pensar, un sentir y/o un decir de manera distinta. (2007:4)

Lo expuesto supone para el proceso educativo "poner en el centro a la persona, especificando algunos ejes centrales de esta dimensión personal: la subjetividad y el cuerpo, elementos de ese conjunto complejo y multidimensional que somos las y los seres humanos". (2007:4). Se correlaciona con ello promover "experiencias sensitivas, donde se busca que el aprendizaje incorpore a los sentidos, que pase por la piel, por el conocimiento del cuerpo y el placer de los sentidos, y también por la reflexión sobre los significados del cuerpo y las implicaciones para la propia vida" (2007: 6).

Además se propone que el aprendizaje se base en el "partir de sí", idea que significa que el aprendizaje se desarrolla a partir de la propia identidad, de los propios deseos, aspiraciones y necesidades, de la propia cotidianidad y de la experiencia vital, pues sólo en esa medida puede ser significativo, y colocarse en el centro a la persona y a sus decisiones para llevarla a su propia transformación de acuerdo a su ideal establecido. Experiencia personal que no se basta en si misma sino que se busca "reflexionarla a la luz de la teoría, es decir, la pedagogía feminista introduce contenidos que son de la vida personal, asumiendo que "lo personal" tiene una dimensión política y que es también objeto de conocimiento y de transformación" e implica también "trabajar con su subjetividad, y buscar la transformación de ésta en miras a que la persona se construya a sí misma de manera más libre, lo cual supone un énfasis en aquellas prácticas y contenidos educativos que coadyuven a esta individuación y desarrollo de la mismidad" (2007:8).

Coincidente con ello, Ríos Everardo plantea "la necesidad de resignificar primero su sí mismo (posición de género), como sus relaciones sociales, familiares y amorosas, en las que sean las mismas personas quienes definan cómo han de funcionar en sus respectivas situaciones de vida, a fin de ir reconstruyendo y modificando las propias condiciones genéricas de vida. Por lo tanto, implica una formación para la vida de las personas, busca entender cómo se constituyen en sujetos, tratando de configurar la unión entre lo íntimo, lo privado y lo público, de una manera que resulte armónica, satisfactoria y productiva para 
cada quien, y a veces también conflictiva y dolorosa, porque implica transformaciones" (2005:126).

Adicional a ello, la argentina Korol, en relación a la pedagogía popular feminista postula que "intentan ser denuncias de las más diversas opresiones. Sería una manera de pensar una pedagogía de los oprimidos, oprimidas, de Ixs ofendidxs de diversas maneras por la cultura capitalista, patriarcal, racista, homofóbica, imperialista, violenta....En esta perspectiva, falible, posible de ser criticada y modificada una y otra vez, que no aspira a ser universal ni válida para todo tiempo y lugar" (2007:17) la cual actúa como una apertura la cual "tienda a desorganizar las relaciones de poder con un sentido subversivo, revolucionario". (2007:18).

Esta pedagogía a su vez se vuelve inconveniente ya que incluso cuestiona al feminismo y sus prácticas porque "hace de la crítica y de la autocrítica un método fundamental; porque sabe que las preguntas abren más caminos que las respuestas y porque no teme al vacío que pueda crear una pregunta sin respuesta porque, tal vez, en ese espacio puedan multiplicarse nuevos ensayos sociales y culturales que no reproduzcan o, incluso, que desafíen las reglas del poder." (2007: 18). Pedagogía que dista mucho de dejar a un* docente en el lugar de autoridad y quien todo lo sabe, por el contrario, I* coloca en el lugar menos jerárquico, con el rol de fomentar las interpelación como parte del aprendizaje que propone, buscando la interpelación no solo a l*s estudiantes sino de sí mismo. Como plantea Ríos Everardo, la pedagogía feminista requiere primero reflexionar sobre nuestras prácticas docentes, sobre como fuimos socializados conforme a nuestro género, clase, etnia, y además formados como docentes y abogad*s para "replantearla, cuestionarla, resignificarla y hacer los cambios necesarios" (2005:140).

Las tres autoras citadas tienen puntos en común en su planteo con los aportes de la educación como práctica de la libertad planteada por Paulo Freire (2015). Esta es retomada por Martínez Marín (2016:130) explicando que "el feminismo, asociado con la pedagogía, implica la superación de una educación entendida como transmisión y reproducción de desigualdades" (2016: 140). Acorde con ello "la pedagogía feminista entiende la educación como un conjunto de procesos y de relaciones de autoridad (que no autoritarismo), donde se reconoce y se respeta al otro y a la otra" (2016:141), coincidiendo con las autoras mencionadas previamente que "al optar por una práctica pedagógica feminista reconocemos que es necesario romper las barreras y narraciones androcéntricas y coloniales, donde se prima una única manera (blanca y masculina) de conocer y donde se legitima una única forma de conocimiento valioso. Por el contrario, reconocer la existencia de una diversidad de saberes que incluyan lo subalterno... sin jerarquizar ni dicotomizar sus conocimientos" $(2016,142)$. A lo cual se suma reconocer la necesidad de hacer una «revolución» de los hombres -y no solo de las mujeres- promoviendo la construcción de nuevas masculinidades. 


\section{V) APORTES PARA LA EDUCACIÓN PRÁCTICA (FEMINISTA) DE GOLDFARD}

Al respecto, haciendo hincapié en la dimensión práctica y vinculado directamente a la educación jurídica nos resultan interesantes los aportes de Goldfard (2005) quien problematiza la relación teoría y práctica -sobre la cual "no existe una separación inherente entre teoría y práctica, sino que hay una interacción permanente entre buena teoría y buena práctica" (2005:83) - y ética feminista y educación práctica. Educación práctica que nos resulta una plataforma para reflexionar sobre nuestra experiencia pedagógica. A lo largo de su trabajo El espiral entre la teoría y la práctica. La ética del feminismo y la educación práctica se centra en comparar algunos de los métodos, como categorías enunciativas y no taxativas, de los feminismos, y de la educación práctica en las facultades de derechos norteamericanas y que en el contexto latinoamericano y en facultades bastante antiguas requiere de adaptaciones.

A los fines este trabajo tomaremos sus referencia a los "métodos feministas" los cuales considera que ninguno " e basa explícitamente en la metodología tradicional de una determinada disciplina....La metodología feminista es deliberadamente ecléctica, desalientas las separaciones tradicionales de ideas relacionadas y promueve el pensamiento interdisciplinario" (2005:90). Los métodos que identifica son:

- Concientización (2005:92 y ss.). Es un método colectivo, interpersonal y reflexivo que tiene como objetivo mejorar la compresión e interpretación de las experiencias vividas. Este se desarrolló a partir de las mujeres, impulsadas por una compartida sensación de necesidad, se unieron para contarse entre sí sus experiencias de vida que en un proceso cooperativo de contar y escuchar muchas advirtieron las similitudes y las repeticiones que surgían de dicha vivencias. Cuando empezaron a surgir ciertos patrones comunes en sus historias, se evidencia la naturaleza colectiva de estas diversas situaciones lo cual lleva a vislumbrar "la dimensión social de la experiencia individual y la dimensión individual de la experiencia social" a partir de lo cual las reacciones a sus experiencias tomaron la forma de crítica estructural. Al respecto plantea que reconocer el dolor o la experiencia propia y animarse a expresarlo en una cultura en la que nunca se ha reconocido la experiencia de tal dolor, ni la validez de tal experiencia es una proeza extraordinaria para encontrar las palabras que puedan transmitir ese conocimiento. Mac Kinnon es una de las referentes de esta metodología aunque como metodología recibió críticas desde el feminismo negro en pensar lo femenino como universal.

- Narración de experiencias personales (2005: 94 y ss). Si bien tiene muchos puntos en común con la concientización esta permite poner en crisis distintas teorías si se pone en evidencia que estas no contemplan determinadas situaciones particulares. A su vez ha permitido que mujeres de color, lesbianas, mujeres pobres y mujeres incapacita- 
das confronten distintas teorías feministas que no las tenían en cuenta, además es un antídoto ante la aplicación de reglas preestablecidas a historias estandirizadas y descontextualizadas. Además al acudir a las experiencia y sentimientos del narrador, las historias pueden movilizar emocional e intelectualmente a ${ }^{*}$ s oyentes, de este modo es posible una comprensión más profunda de la, que frecuentemente, surge del razonamiento analítico.

- Preguntas sobre la exclusión (2005:98 y ss): Se utilizan para desarrollar una teoría estructural a partir de las narraciones que utiliza la concientización. Formular tales preguntas lleva necesariamente a indagar porque se excluyen determinadas necesidades, perspectivas y experiencias femeninas de la propia ley o de otras instituciones sociales y políticas. Las participantes pueden identificar formas institucionales que excluyen a cierto grupo de mujeres, o experiencias que no forman parte de la socialización de las masculinidades, por ejemplo el miedo a la violación. Ello ayuda a no entender el problema de género aislado de otras estructuras sociales dado que las mujeres son afectadas por cuestiones relacionadas con las razas, clases, culturas, orientaciones sexuales y habilidades físicas.

Dichos métodos formarían parte un razonamiento contextual cuyo valor reside en su capacidad de ampliar el contexto, explica, hacer una constante búsqueda y prestar especial atención a perspectivas e intereses que, de otro modo, pasarían inadvertidos, por no resultar familiares, cercanos y que han ayudado a una crítica epistemológica del derecho. Al respecto plantea como la educación práctica cuenta con potencialidades pero resulta poco conocida para identificar la posibilidades y los límites del derecho, la posibilidad que esta de enriquecer a los cursos teóricos subvirtiendo de alguna manera los cánones tradicionales de enseñanza. En dicha sintonía las herramientas interdisciplinarias constituyan un recurso para comprender los casos y fallos más allá de la historia concreta. Premisa que es compartida por Di Corletto (2020:59) quien considera que para asegurar la incorporación de la perspectiva de género sumar variadas fuentes de producción del conocimiento, como un collage que combine análisis historiográficos, sociológicos, antropológicos que obliguen a cambiar de manera constante la lente con la cual se mira el derecho. Componentes, potencialidades y métodos posibles de una pedagogía feminista que pondremos a jugar en un caso una experiencia pedagógica concreta

\section{VI) REFLEXIONES A PARTIR DE UNA EXPERIENCIA PEDAGÓGICA}

Para pensar la puesta en práctica de lo señalado hasta el momento elegimos reconstruir la experiencia de una clase, contemporánea a estas reflexiones, realizada en septiembre de 2019 con una carga horaria de 2 horas en el marco del seminario de Grado "Feminismo 
y Derecho Penal" titulada Algunas aproximaciones para pensar el rol del derecho penal ante delitos contra la integridad sexual a la luz de las pedagogías de la crueldad. Considerando que no soy especialista en derecho penal (todo lo contrario) y de hecho mi convocatoria fue en función de mi recorrido de investigación en temáticas vinculadas a los género (s), para la clase retome un tema del cual veníamos trabajando y discutiendo bastante en el Área de Estudios de Género del Instituto de Cultura Jurídica -sin saberlo desde una marcada pedagogía feminista como dinámica de dicha Área- y a partir de ello proponer algunas aproximaciones desde los estudios de género y diversidad a un tema puntual: la violación hacia las mujeres.

\section{Para pensar la puesta en práctica de lo señalado hasta el mo- mento elegimos reconstruir la experiencia de una clase, con- temporánea a estas reflexiones, realizada en septiembre de 2019 con una carga horaria de $\mathbf{2}$ horas en el marco del semi- nario de Grado "Feminismo y Derecho Penal" titulada Algunas aproximaciones para pensar el rol del derecho penal ante delitos contra la integridad sexual a la luz de las pedagogías de la crueldad.}

La elección de reconstruir esta experiencia se justifica en primer lugar por lo movilizante que fue a nivel subjetivo. En segundo lugar porque rompe con los cánones pedagógicos tradicionales y desde la ciencias de la educación resulta una innovación a las estrategias didácticas utilizadas hegemónicamente en la FCJyS que retomando a Lucarelli es una práctica de enseñanza "que altera, de alguna manera, el sistema de relaciones unidireccional que caracteriza una clase tradicional, conducente a una "didáctica de la transmisión" que, regida por la racionalidad técnica, reduce al estudiante a un sujeto destinado a recepcionar pasivamente cualquier información. Innovar, en consecuencia significa alterar el sistema relacional intersubjetivo de una clase." $(1997,14)$. Además conforme lo postula Herrera, lo referente a "la sexualidad (el cuerpo) suelen ser terrenos sensibles y hábiles a la vez para producir ciertas revueltas (revoluciones) jurídicas" $(2017,104)$

En ese sentido las fuentes utilizadas para preparar la clase fueron múltiples y dispares, lo cual se encuentra justificado en buscar insumos en otras disciplinas y con otros formatos que excedan a los trabajos de doctrina o a la jurisprudencia. Y retoma un poco lo ecléctico que implican los métodos del feminismo y la riqueza que permite la interdisciplina para mirar desde diferentes lentes y ampliar el contexto más allá de los casos en si, como plantea Di Corleto (2020). A partir de dichos insumos se buscó formular preguntas que propondríamos como parte de la actividad de la clase y a partir de allí compartir sus respuestas y pro- 
blematizar algunas cuestiones con l*s estudiantes y con la intensión de finalizar la clase dejándoles el deseos de seguir leyendo sobre el tema.

En ese sentido las fuentes utilizadas para preparar la clase fueron múltiples y dispares, lo cual se encuentra justificado en buscar insumos en otras disciplinas y con otros formatos que excedan a los trabajos de doctrina o a la jurisprudencia. $Y$ retoma un poco lo ecléctico que implican los métodos del feminismo y la riqueza que permite la interdisciplina para mirar desde diferentes lentes y ampliar el contexto más allá de los casos en si, como plantea Di Corleto (2020).

Me encontraba con I*s estudiantes por primera vez en dicha oportunidad, más allá de algunas consideraciones que me había proporcionado la coordinadora, era un grupo reducido de aprox. 10 estudiantes y que salvo uno de los coordinadores eran todas mujeres, en su mayoría en mitad de la carrera, de entre 20 y 30 años, por lo cual, salvo la presencia del otro integrante de la cátedra no pudo trabajarse con varones el identificar algunas cuestiones en cuanto a la construcción de las masculinidades, los mandatos, estereotipos. La primera actividad a realizarse durante la clase fue deliberadamente osada buscando partir de sí y revalorizar la experiencia y la práctica, e implicó el uso de narraciones de historias personales, propias, conocidas o cercanas, que por lo que podría movilizar a nivel emocional y para preservarnos mínimamente de ello se propuso como individual y anónima. Se le propuso a las estudiantes y al staff docente responder a las siguientes preguntas "¿He tenido miedo a la violación?, ¿Cuándo?, ¿Por qué?, ¿Conozco en mi entorno personas que hayan sufrido violación?, ¿Qué conductas de mi vida realizo en función del miedo a la violación?". En el caso de que quisieran compartir la respuesta debía escribirse en un papel y colocarse con un seudónimo en un sobre lo cual implicó revisar nuestra propia experiencia personal y nuestra socialización. Recordemos que en el derecho androcéntrico y patriarcal, a dichas experiencias no se les da valor ni se considera parte o un medio en la construcción del conocimiento.

Posteriormente se explicó que la propuesta de la clase podría ser trabajar con insumos diferentes de tres autoras con perfiles, pertenencias disciplinares y trayectorias muy diferentes. Insumos que fueron presentados en conjunto con una mini bibliografía de las tres autoras feministas que lo producían como parte de la epistemología feminista y queer propuesta: Rita Segato antropóloga con experiencia en la investigación en temas de género en diferentes países de Latinoamérica, Virginie Despente ensayista y novelista francesa, y Inés Hercovich psicóloga social e investigadora en termas de violación. Los insumos 
respectivamente fueron, la introducción al texto "Hacia una contra-pedagogía de la crueldad" ${ }^{\prime \prime}$, que son las desgravaciones de un curso dado por la autora, un extracto del ensayo "La Teoría de King Kong" en el capítulo que se titula "Como violar a una mujer tan viciosa" donde se relata una experiencia personal y el video "Negociar Sexo por vida".

En base a ello, en lugar de imponer y decidirlo todo desde el poder que me da mi rol docente, se les expuso a las estudiantes la posibilidad que eligieran entre el ensayo y el video, eligieron trabajar con el video, previo a leer el fragmento del libro de Rita Segato. En base a ello la propuesta era responder las siguientes preguntas: ¿Cuál es el mensaje simbólico que emiten los/as abuso/violación?, ¿Con que insumos teóricos vemos y co-construimos los hechos?, ¿Qué pruebas produzco o necesito?, ¿Qué lógicas legitiman o subvierten los procesos?, ¿Qué argumentos se usan al momento de acusar, defender y juzgar?, ¿Qué se sanciona o que se premia?, ¿Quiénes?, ¿Cómo se sanciona?, ¿Cómo lo pienso con perspectiva de género y diversidad?. Preguntas que nos abrieron a través de su respuesta pensar preguntas de exclusión, en el sentido de cuestionar si toda las personas, si ello variaba con la edad, la clase social o la etnia, y especialmente los varones estaban incluidos en la experiencia y cómo.

A partir de las preguntas, y sus respuestas donde los insumos teóricos nos permitieron pensar el contexto buscamos abordar temas tales como el disciplinamiento que implica la violación y el concepto proporcionado por Rita Sagato sobre pedagogía de la crueldad ${ }^{8}$ y aquello que pudiese surgir de la socialización de las narraciones de experiencias personales que fueron recuperadas en el pizarrón. Finalmente las respuestas a las primeras preguntas no se leyeron como tal y fue deliberado ya que la idea era sensibilizar y trabajar con el propio registro y que no implicará una exposición personal ya que ante la propuesta se observó una situación de sorpresa y resistencia al comienzo en un auditorio que entre si no existía previamente una relación de confianza o militancia compartida.

Igualmente las estudiantes fueron retomando espontáneamente a lo largo de la clase dichas respuesta comentando sus experiencias, y quienes estaban presentes pudieron identificar o al menos poner en palabras y compartirlo como parte de una experiencia social situaciones de abuso sexual cercanas y que confirmaban lo que planteaba el video

\footnotetext{
5 Segato Rita (2018). Contra-pedagogía para la crueldad. Presentación. Crueldad: pedagogías y contra pedagogías. Pág. 11 a 16.

6 Despente Virgine (2007). La teoría de King Kong. Fragmento: Imposible violar a una mujer tan viciosa. Pág. 29 a 35

$7 \quad$ Hercovich Inés (2015). Charla Ted: Negociar Sexo por vida. Disponible en https://www. youtube.com/watch?v=iPk9VTATmGM. 17 Minutos

8 Rita Segato $(2018,11)$ entiende por pedagogía de la crueldad a todos los actos y prácticas que enseñan, habitual y programa a los sujetos a trasmutar lo vivo y a su vitalidad en cosas. En ese sentido, esta pedagogía enseña algo mucho más allá de matar, enseña a matar de una muerte desritualizada, de una muerte que deja apenas residuos en el lugar del difunto.... Me refiero a algo muy precioso, como es la captura de algo que fluía errante e imprevisible, como es la vida, para instalar allí la inercia y la estabilidad de la cosa, mensurable, vendible, comprable, obsolente.. el ataque sexual y la explotación sexual de las mujeres son hoy dos actos de rapiña y consumición de los cuerpos que constituyen el lenguaje más preciso con que la cosificación de la vida se expresa.
} 
y que en palabras de Goldfaber permitió ver la relación dialógica entre lo individual y lo social. Se verificó nueva y tristemente que resultaba una situación más cercana y frecuente de lo que se esperaba e incluso deseaba, en la cual no eran las únicas que, o bien las habían sufrido, o resultaban cercanas a ella, y que quizás fue uno de los primeros, pocos e inesperados espacios donde pudieron hablarla y que su experiencia tuviera valor en la construcción del conocimiento.

Entonces no solo en base a la teoría sino también a la experiencia vimos como es mínimo el número de casos que se formulan denuncias, que llegan a la justicia, aun más pequeño aquellos casos que terminan con condenas. Allí se pudo visibilizar en base a sus experiencias, todo lo que implica a nivel subjetivo y social poder hablarlo, sus consecuencias, el miedo, la culpabilización, que los agresores no son prototipo de desconocidos de clase baja sino que son personas que "manifestaban quererlas" y que tanto la experiencia como el miedo a la misma condicionan la vida de las mujeres. Tal como pudo cotejarse cuando le consultamos al docente varón presente si sus respuestas y experiencias se asemejaban o lejos estaban de ello y si la clase le había servido para poder pensar una realidad que le resultaba lejana. Experiencia pedagógica que si habilito a poder re plantearse entre todas las personas presentes cómo se construyen los mandatos de las masculinidades en torno a la sexualidad y los castigos que existen dentro de los grupos de varones a quienes no cumple con ello, o los diálogos que se producen entre padres e hijas. Volviendo a lo teórico a vez abordamos como se construye el testimonio de las mujeres que han sufrido violencia sexual e incluso las emociones que se juegan en l*s quienes en la mayoría de los casos no están preparado para ell*s y que constituían espacios donde ellas como operador*s quizás ya estuvieran trabajando o en un futuro no muy lejano pudieran está ocupando.

En ese sentido sin pensar en ese momento tanto en la pedagogía feminista y su implementación la experiencia en cierta medida estuvo atravesado por esta y por los métodos feministas ya que busco identificar el orden de los género y de la heteronormatividad y mínimamente proponer algunas pequeñas claves para plantear como se puede de-construir y construir de una manera más igualitaria. La clase procuro ir a lo cercano, conocido, a la práctica, a partir de la experiencia de sí, a lo que emocionalmente nos pasa por el cuerpo y la subjetividad, a socializar las experiencias y repensar a la luz de la teoría, a dejar que la clase tenga el rumbo que ${ }^{*}$ s estudiantes quieran, eligiendo entre las lecturas de diferentes disciplinas dentro del feminismo.

Asimismo, operó aquella propuesta de Hererra de "generar otros modos comunicacionales de vincularse con los alumnos a quienes se los traslada sin moverlos del aula a situaciones bien disimiles leídas en primera persona" (2017:114). Experiencia educativa que tanto en su planificación, ejecución, reflexión posterior a partir del diálogo con docentes y estudiantes, y su reconstrucción, recuperó aquello de divisar y explicitar que tanto el fondo como la forma en que se comunica el conocimiento jurídico constituyen un eje central en cómo se lo percibe y se lo vive, y esto no es menor. Entender el derecho como una herramienta de dominación social lleva consigo el genuino interés por indagar sobre 
cómo se estructura, las razones de su rigidez, verticalidad, poder y su calidad de exclusivo y excluyente" (Hererra 2017:92).

El fundamento de poder pensar la(s) pedagogía(s) feminista(s), los métodos del feminismo que pueden utilizarse en la enseñanza y sus alcances es poder trascender a las experiencias individuales que, en la cotidianeidad docente generalmente no tenemos el tiempo y la práctica de reflexionar y problematizar. Teniendo en consideración que I*s docentes son sujetos históricos y su contexto, somos capaces de transformaciones, especialmente cuando nos sentimos protagonistas de su hacer profesional como plantean Da Cunha y Lucarelli (2006). Ello en la medida que estemos dispuestos a romper con el conservadurismos, revisarnos, salir de lo conocido, y a cuestionarnos íntegramente -en lo personal y como docentes-, rompiendo lo solitario e individual, en espacios colectivos entendiendo como colectivo al intercambio al menos con otr*s coleg*s, con I*s estudiantes. A ello se suma la necesidad de lecturas de género y diversidad que nos garanticen además de la perspectiva de género y diversidad, y la formación docente, requisito mínimo para implementar una pedagogía feminista.

\section{El fundamento de poder pensar la(s) pedagogía(s) feminista(s), los métodos del feminismo que pueden utilizarse en la ense- ñanza y sus alcances es poder trascender a las experiencias in- dividuales que, en la cotidianeidad docente generalmente no tenemos el tiempo y la práctica de reflexionar y problematizar.}

La clase siguiendo el modelo de la dogmática jurídica podría haber sido una exposición en base a normativa y doctrina, cumplir con el canon tradicional, y en el mejor de los casos incluir el análisis de un fallo, nuevamente reproduciendo todo aquello que señalamos previamente. Decidimos, con la coordinadora del Seminario, poner en práctica aquello que plantea Avila Cambeiro respecto de pensar no solo sobre que enseñamos sino sobre cómo lo enseñamos" (2014:116). Puede que haya resistencias propias de la socialización de l*s estudiantes y l*s docentes, e incluso del propio poder y lugar de privilegio que detentan dentro las jerarquías que ocupan l*s docentes pero como señalaba Herrera retomando a Simone de Beauvoir la libertad tiene más riesgos que la esclavitud. 


\section{BIBLIOGRAFÍA}

Álvarez Raúl N (2012). Cómo enseñar teoría crítica del estado. Revista Academia. Facultad de Derecho UBA. Buenos Aires. Año 10, Nro. 20, pág. 17. Disponible en: http://www.derecho.uba.ar/publicaciones/rev_academia/revistas/20/como-ensenar-teoria-critica-del-estado.pdf (19/9/2019)

Andriola, K. y Goga, D. (2014). "Las mujeres en la Facultad de Ciencias Jurídicas y Sociales" En La formación de abogados y abogadas: nuevas configuraciones. Capítulo VIII. Facultad de Ciencias Jurídicas y Sociales. Universidad Nacional de La Plata.

Andriola, K. A (2019). “Epistemología, metodología feminista y $i$ una pedagogía feminista? para la enseñanza del Derecho". IX Jornadas sobre Enseñanza del Derecho (Facultad de Derecho, UBA, 3 y 4 de octubre de 2019.

Andriola, K. (2018). "La enseñanza de los procesos de determinación de la capacidad de las personas con padecimientos mentales o discapacidad mental: entre el curriculum formal y el real". Trabajo Final Integrador. Especialización en Docencia Universitaria. Universidad Nacional de La Plata. Disponible en: http://sedici.unlp.edu.ar/handle/10915/68932

Andriola, K. A. y Cano, J. E. (2017). “La perspectiva de género en la formación de grado de los abogados en la FCJyS-UNLP. Su reflejo en las asignaturas Derecho Constitucional y Derecho Internacional Público". XVIII Congreso Nacional y VIII Latinoamericano de Sociología Jurídica (Universidad Nacional de Cuyo, 10, 11 y 12 de octubre de 2017). Facultad de Ciencias Jurídicas y Sociales.

Ávila Cambeiro María Gabriela (2014). Enseñar a aprender en derecho: Revista Academia. Facultad de Derecho UBA. Buenos Aires. Año 12, Nro. 24, pág. 111. Disponible en: http://www.derecho.uba.ar/publicaciones/rev_academia/revistas/24/ensenar-a-aprender-en-derecho.pdf (11/9/2019)

Bauger Erika Silvina (2019). Perspectiva de géneros y feminismos jurídicos en la enseñanza del derecho. Revista Derechos en Acción. Año 4/No 11 Otoño 2019. Disponible en https://revistas.unlp.edu.ar/ReDeA/article/ view/7540/6718. (19/9/2019)

Benente Mauro (2017). Derecho y Derecha. Enseñanza del derecho y despolitización. Publicado en la Revista de Derecho Penal y Criminología. Año VII. Nro. 1. Buenos Aires. La Ley.

Bianco Carola y Marano Gabriela (2008). La formación de los abogados y la lucha por el Derecho: apuntes para la vinculación entre la constitución del campo jurídico en el contexto latinoamericano y la enseñanza del derecho. 
El caso de la Facultad de Ciencias Jurídicas y Sociales de la UNLP. Revista Anales. Buenos Aires. La Ley. Nro. 39. Pág. 577

Blazquez Graf Norma (2012). Epistemología feminista. En Blázquez Graf. N et al. (coord.). Investigación feminista: epistemología, metodología y representaciones sociales. México D.F. UNAM. Pág. 21

Busquet Corletto Ana Gabriela (2011). Transversalizar la perspectiva de género en la educación superior. Problemas conceptuales y prácticos. Revista Perfiles educativos. Volumen XXXIII, número especial, 2011. IISUE. UNAM. Pág. 211. Disponible en http://www.scielo.org.mx/pdf/peredu/v33nspe/ v33nspea18.pdf (10/05/2020)

Camilloni Alicia (2011). La formación docente como política pública: consideraciones y debates. Disponible en: http://fh.mdp.edu.ar/revistas/index. php/r_educ/article/view/43/87. (11/9/2019)

Cano Julieta E (2019). La sociología en la formación de abogados y abogadas: el sentido de la inclusión de la problemática de las violencias basadas en el género. En González Manuela, Miranda Marisa, Zaikosky Biscay Daniela (coordinadoras). Género y Derecho. UNLPam. Pág. 341. Disponible en http://www.unlpam.edu.ar/cultura-y-extension/edunlpam/catalogo/actas-de-eventos-academicos/genero-y-derecho(10/5/2020)

Calzadilla Medina Maria Aranzazu y Hernadez Torres Estefanía (2018). La experiencia en innovación educativa de un Área de conocimiento: *promoción de la igualdad de género desde el Derecho Civil. Revista Educación y Derecho Nro. 17. Disponible en DOI: http://dx.doi.org/10.1344/REYD2018.17.23500 $(10 / 5 / 2020)$

Costa Wesgman Malena (2017) Formación jurídica y androcentrismo. Discusiones XIX. Educación jurídica. Pág. 14. Disponible en: http://revistadiscusiones.com/wp-content/uploads/2018/09/DiscusionesXIXedicio\%CC\%81n. pdf (10/9/2019).

Di Corleto, Julieta (2020). Doctrina penal feminista en Ronconi Liliana Mabel. La enseñanza del derecho con perspectiva de género: herramientas para su profundización. Ciudad de Buenos Aires. Universidad de Buenos Aires. Colección de Publicaciones de Resultados de Proyectos de Investigación Científica. Disponible en http://www.derecho.uba.ar/investigacion/pdf/ensenanza-con-perspectiva-de-genero.pdf

Da Cunha Maria Isabel y Lucarelli Elisa (2006). Innovación en el aula universitaria y saberes docentes: experiencias de investigación y formación que aproximan a Argentina y Brasil. Disponible en: http://www.sc.ehu.es/ 
Ditieri Marina y Cortese Gilda (2019).¿Puede garantizarse el derecho a la educación sin perspectiva de género?. Algunas reflexiones sobre la situación actual de la Facultad de Derecho de la Universidad de Buenos Aires.

Freire Paulo (2015), La educación como práctica de libertad. Buenos Aires. Argentina. Siglo XXI.

Fries Monleon Lorena y Lacrampettte Nicole (2013). Feminismo Género y Derecho en Derechos Humanos y Mujeres: Teoría y práctica. En Lacrampette, N. et al (2013). Derechos humanos y mujeres: teoría y práctica. Disponible en https://doi.org/10.34720/c3af-6b42

Goldfard Philis (2005).El espiral entre la teoría y la práctica. La ética del feminismo y la educación práctica. Revista Academia Nro. 6- Año 2005- Pág. 67. Disponible en http://www.derecho.uba.ar/publicaciones/rev_academia/ revistas/06/una-espiral-entre-la-teoria-y-la-practica.pdf (15/05/2020)

González Manuela (2019). El género como recurso de la enseñanza legal. En González Manuela, Miranda Marisa, Zaikosky Biscay Daniela (coordinadoras). Género y Derecho. UNLPam. Pág. 271. Disponible en http://www.unlpam. edu.ar/cultura-y-extension/edunlpam/catalogo/actas-de-eventos-academicos/genero-y-derecho(10/5/2020)

González Manuela y Cardinaux Nancy (coomp). (2009). Los actores y sus prácticas. La Plata. Edulp.

González Manuela y Marano Gabriela (comp) (2014). La formación de abogados y abogadas. Nuevas Configuraciones. La Plata. Edulp.

Heim Daniela (2019) La perspectiva de género en la enseñanza del derecho penal y procesal penal. Aportes para su inclusión. Ponencia presentada el III Congreso Internacional de Enseñanza del Derecho, FCJyS UNLP. http:// ensenanzaderecho.jursoc.unlp.edu.ar/documentos/ponencias2018/jue/ HEIM,\%20Daniela.pdf(10/5/2020)

Herrera Marisa (2017). Los cambios legislativos como motor para la deconstrucción de la enseñanza del derecho. Disponible en: http://www. derecho.uba.ar/publicaciones/rev_academia/revistas/29/los-cambios-legislativos-como-motor-para-la-deconstruccion-de-la-ensenanza-del-derecho-de-las-familias.pdf (11/9/2019)

(1996). Perspectiva de Género. La Tarea, Revista de Educación y Cultura de 
la Sección 47 del SNTE. No. 8. Enero- marzo 1996. Disponible en www.ses. unam.mx/curso2007/pdf/genero_perspectiva.pd (12/12/2016)

(1999). Usos, dificultades y posibilidades de la categoría género. Papeles de Población 1999 5. Pag. 21. Disponible en http://www.redalyc.org/ html/112/11202105 (1/3/2018)

Lucarelli Elisa (2004). Prácticas Innovadoras en la Formación del Docente Universitario Educação, vol. XXVII, núm. 54, setembro-dezembro, 2004, pp. 503-524, Pontifícia Universidade Católica do Rio Grande do Sul Brasil. Disponible en http://pdfhumanidades.com/sites/default/files/apuntes/LUCARELLI\%20Pr\%C3\%A1cticas\%20Innovadoras.pdf (10/5/2020)

Lucarelli Elisa (1997). Teoría y práctica como innovación en docencia, investigación y actualización pedagógica. Cuaderno de Investigación No. 10.Bs. As. UBA. FFyL.IICE.

Kennedy Duncan

(2004). La educación legal como preparatoria para la jerarquía. En: Revista Academia Nro. 3. Año 2. Buenos Aires. Facultad de Derecho UBA. Pág. 117 (2007). Politizar el aula. Revista Academia Nro. 10. Año 5. Buenos Aires. Facultad de Derecho UBA Pág. 85

Mac Kinnon Catherina. (2005). Integrando el feminismo a la educación práctica. En: Revista Academia Nro. 6. Año 3. Buenos Aires. Facultad de Derecho UBA. Pág. 157

Korol Claudia (2007). La educación como práctica de la libertad en AAVV Hacia una pedagogía feminista Géneros y educación popular Pañuelos en Rebeldía. Colección Cuadernos de Educación Popular Editorial el Colectivo. Buenos Aires. Disponible en: https://libros.metabiblioteca.org/bitstream/001/434/1/ Hacia\%20una\%20pedagog\%C3\%ADa\%20feminista.pdf (19/9/2019)

Lerussi Romina (2017) Tomar el Derecho. Revista Discusiones XIX. Educación jurídica. Pág. 5. Disponible en: http://revistadiscusiones.com/wp-content/uploads/2018/09/DiscusionesXIXedicio\%CC\%81n.pdf (10/9/2019)

\section{Maceira Ochoa Luz}

(2006). Más allá de la coeducación: pedagogía feminista. Revista educar: Coeducación, Num. 36, Guadalajara, Secretaría de Educación Jalisco. Disponible en https://www.academia.edu/3348187/M\%C3\%A1s_all\%C3\%A1_de_ la_coeducaci\%C3\%B3n_pedagog\%C3\%ADa_feminista(11/9/2019)

(2007). Una propuesta de pedagogía feminista: teorizar y construir desde el género, la pedagogía, y las prácticas educativas feministas. Ponencia presentada en el "I Coloquio Nacional Género en Educación". Universidad Pedagógica Nacional - Fundación para la Cultura del Maestro, AC. México. Disponible en https://www.academia.edu/3348598/Una_propuesta_de_pedagog\%C3\%A- 
Da_feminista_teorizar_y_construir_desde_el_g\%C3\%A9nero_la_pedagog\%C3\%ADa_y_las_pr\%C3\%A1cticas_educativas_feministas (20/9/2019)

(2008). El sueño y la práctica de sí. Pedagogía feminista. Una propuesta. México DF. El Colegio de México, Centro de Estudios Sociológicos. Programa interdisciplinario de Estudios de Género. Disponible en https://www.academia.edu/3321203/El_sue\%C3\%B1 o_y_la_pr\%C3\%A1ctica_de_s\%C3\%AD. Pedagog\%C3\%ADa_feminista._una_propuesta(11/9/2019)

Martínez Martín, Irene (2016). Construcción de una pedagogía feminista para una ciudadanía transformadora y contra-hegemónica. Foro de Educación, 14(20), 129-151. Disponible en: https://dialnet.unirioja.es/servlet/articulo?codigo $=5354751(11 / 9 / 2019)$

Misse Miquel y Miriam Sola (2009). La lucha trans por la despatologización, lucha transferminista. Jornadas feministas estatales. Granada, España, 2009. Disponible en: http://www.feministas.org/IMG/pdf/no_binarismos_Miriam_ Miquel.pdf (11/9/2019)

Piccone María Verónica (2018) Género y enseñanza del derecho. Abordaje crítico en el marco del proceso de acreditación de las carreras de abogacía. Ponencia presentada en las XIX Congreso Nacional de Sociología Jurídica y XI Congreso Latinoamericano. Facultad de Derecho de la UBA. https://rid. unrn.edu.ar/jspui/bitstream/20.500.12049/4361/1/Publicaci\%c3\%b3n\%20 Congreso\%20SASJU\%20PICCONE.pdf (10/5/2020)

Ríos Everardo, Maribel (2015). Pedagogía feminista para la equidad y el buen trato. Revista Internacional de Ciencias Sociales y Humanidades, SOCIOTAM, vol. XXV, núm. 2, julio-diciembre, 2015, pp. 123-143 Universidad Autónoma de Tamaulipas Ciudad Victoria, México. Disponible en: https://www. redalyc.org/articulo.oa?id=65452536007 (10/9/2019)

Viturro P. (2005). Constancias. En: Revista Academia Nro. 6. Año 3. Facultad de Derecho UBA. Pág. 295

\section{Zaikosky Biscay Daniela}

(2018). “Derecho que no se enseña no se aprende, derecho que no se aprehende no se invoca ni se aplica. Aproximaciones a los contenidos sobre violencia de género en la FCEyJ de la UNLPam". En Lell, $\mathrm{H}$.: Actas del II Congreso Internacional Instituciones e interdisciplina: alcances jurídicos, económicos y epistemológicos / Helga Lell; compilado por Helga Lell. - 1a ed compendiada. - SantaRosa: Universidad Nacional de La Pampa. Disponible e https://www.academia.edu/35996095/ Actas_del_II_Congreso_Internacional_Instituciones_e_interdisciplina_alcances_jur\%C3\%ADdicos_econ\%C3\%B3micos_y_epistemol\%C3\%B3gicos

(2019). La formación legal y la violencia contra las mujeres. El caso de la FCEyJ, UNLPam (2016 y 2017). En González Manuela, Miranda Marisa, Zai- 
kosky Biscay Daniela (coordinadoras). Género y Derecho. UNLPam. Pág. 293.

Disponible en http://www.unlpam.edu.ar/cultura-y-extension/edunlpam/ catalogo/actas-de-eventos-academicos/genero-y-derecho 